\title{
Flow simulation for a horizontal well with slotted screen and ICD completions based on the wellbore-annulus-transient seepage reservoir model
}

\author{
Wei Luo****, Ruiquan Liao*, Jing Wang**, Hongying Wang**, Zilong Liu* and Yang Cheng* \\ * State Key Laboratory of Shale Oil and Gas Enrichment Mechanisms and Effective Develpment, Beijing, China \\ * Sinopec Key Laboratory of Shale Oil/Gas Exploration and Production Technology, Beijing, China \\ * Petroleum Engineering Institute of Yangtze University, Wuhan, Hubei, China \\ * Key Laboratory of Drilling and Production Engineering for Oil and Gas, Hubei Province. Wuhan, China \\ * Laboratory of Multiphase Pipe Flow, Gas Lift Innovation Center, China National Petroleum Corp, Yangtze University, Wuhan, China \\ ** Research and Development Center, Tuha Oil Field Company, PetroChina, Hami, Xinjiang 839009, China \\ *** Corresponding Author: luoruichang@163.com
}

$\begin{array}{ll}\text { Submitted } & : 20 / 09 / 2020 \\ \text { Revised } & : 10 / 08 / 2021 \\ \text { Accepted } & : 22 / 08 / 2021\end{array}$

\begin{abstract}
A flow is observed in the pipe for the horizontal section of slotted screen completion and inflow control device (ICD) completion, and an annulus flow exists between the pipe and the borehole wall. Based on the principles of mass conservation and momentum conservation, a model for variable mass flow in an oil reservoir to simulate wellbore-annulus-reservoir state in the horizontal section of slotted screen completion and ICD completion is proposed. Consequently, based on the newly established formation transient seepage model and wellbore and annulus variable mass flow model, an accurate prediction of the production rate of a horizontal well and optimized design parameters for slotted screen completion and inflow control device (ICD) completion are achieved. The predicted flow profiles of the established model are confirmed using the simulation software from Computer Modeling Group Ltd. When external casing packers are not considered, findings show that the predicted production rates of both slotted screen completion and ICD completion, which are obtained using the variable mass flow models without annulus flow modeling, are higher than the rates obtained using the variable mass flow models with annulus flow modeling. Both models show that the pressure profile and flow profile of the borehole wall are more uniform in wellbore-annulus-reservoir in horizontal wells. The flow model for horizontal wells with annulus flow modeling should be established to improve the accuracy of the predicted production.
\end{abstract}

Keywords: Slotted screen; Inflow control device (ICD); Variable mass flow; Simulate; Formation transient seepage model. 


\section{NOMENCLATURE}

$a$

$B_{o}$

$b$

$C_{j}$

C

$c$

$D_{c}$

$\bar{D}$

D

$d p_{a w, i}$

$d p_{w, i}$

$d p_{f, i}$

$d p_{a c c, i}$

$d p_{m i x, i}$

$d p_{m f, i}$

$d p_{\text {macc }, i}$

$d p_{\text {mmix }, i}$

$d s$

$d x$

$d y$

$d z$

$f_{f, i}$

the intermediate substitution variable

the volume factor of crude oil

the intermediate substitution variable

integral constant of segment $\mathrm{j}$

integral constant

the intermediate substitution variable

the internal diameter of the casings [m]

the equivalent diameter of the annulus (i.e., area equivalent) [m]

the diameter of the center tubing $[\mathrm{m}]$

the loss of annular pressure drop of the $i$ infinitesimal section of the

annulus pipe flow $[\mathrm{Pa}]$

the loss of pressure drop of the $i$ infinitesimal section of the center

cylindrical pipe flow $[\mathrm{Pa}]$

the friction loss in the $i$ infinitesimal section of the center tubing [Pa]

the acceleration loss in the $i$ infinitesimal section of the center tubing $[\mathrm{Pa}]$

the mixing loss in the $i$ infinitesimal section of the center tubing [Pa]

the friction loss in the $i$ infinitesimal section of the annulus [Pa]

the acceleration loss in the $i$ infinitesimal section of the annulus [Pa]

the mixed pressure drop loss of the annular area of the $i$ infinitesimal

section $[\mathrm{Pa}]$

the full differential of $s$ (or the length of the $i$ infinitesimal section that is equal to $\Delta s)[\mathrm{m}]$

the differential of the independent variable $\mathrm{x}[\mathrm{m}]$

the differential of the independent variable $y[\mathrm{~m}]$

the differential of the independent variable $\mathrm{z}[\mathrm{m}]$

the frictional factor of the $i$ infinitesimal section 


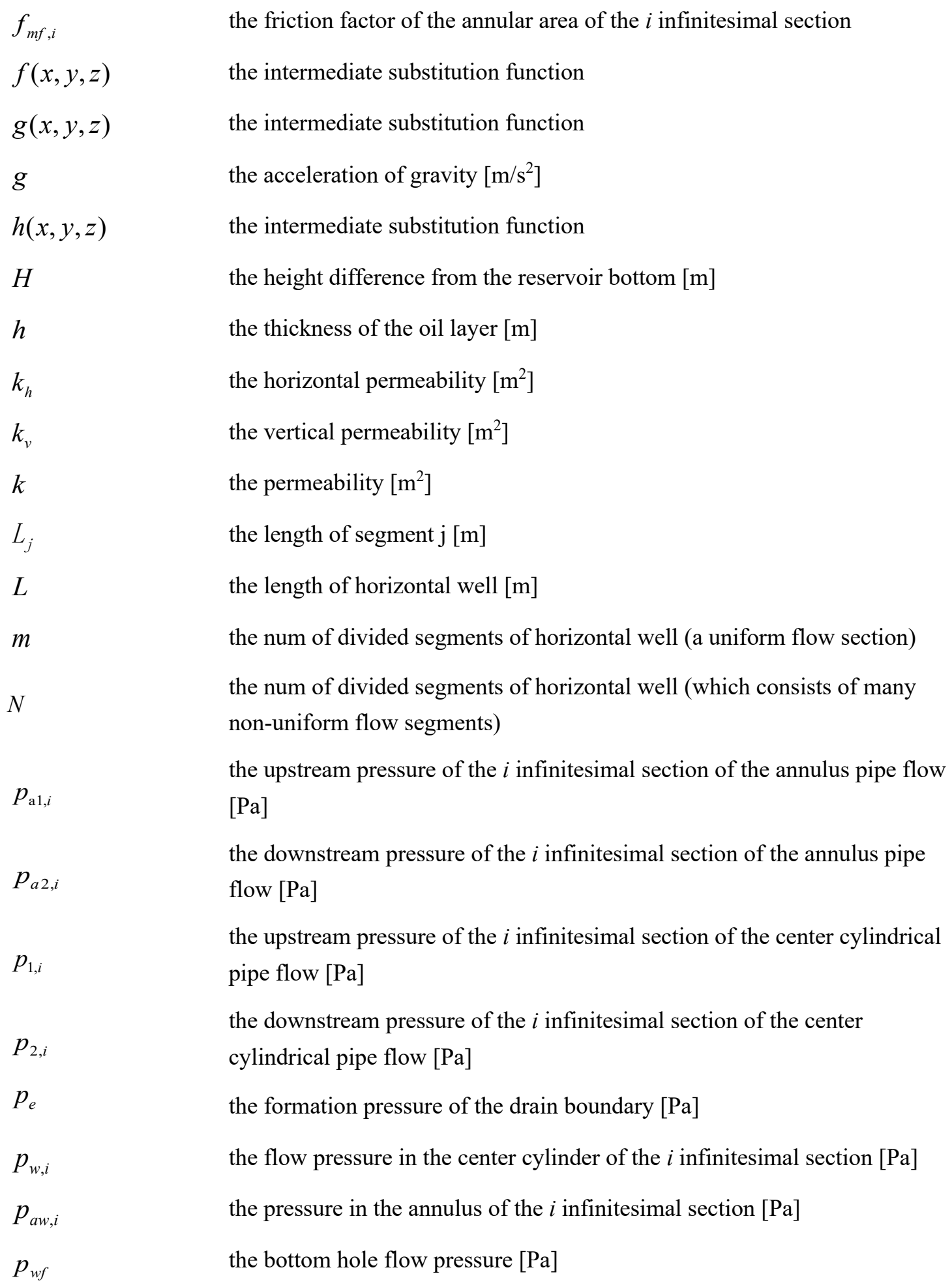




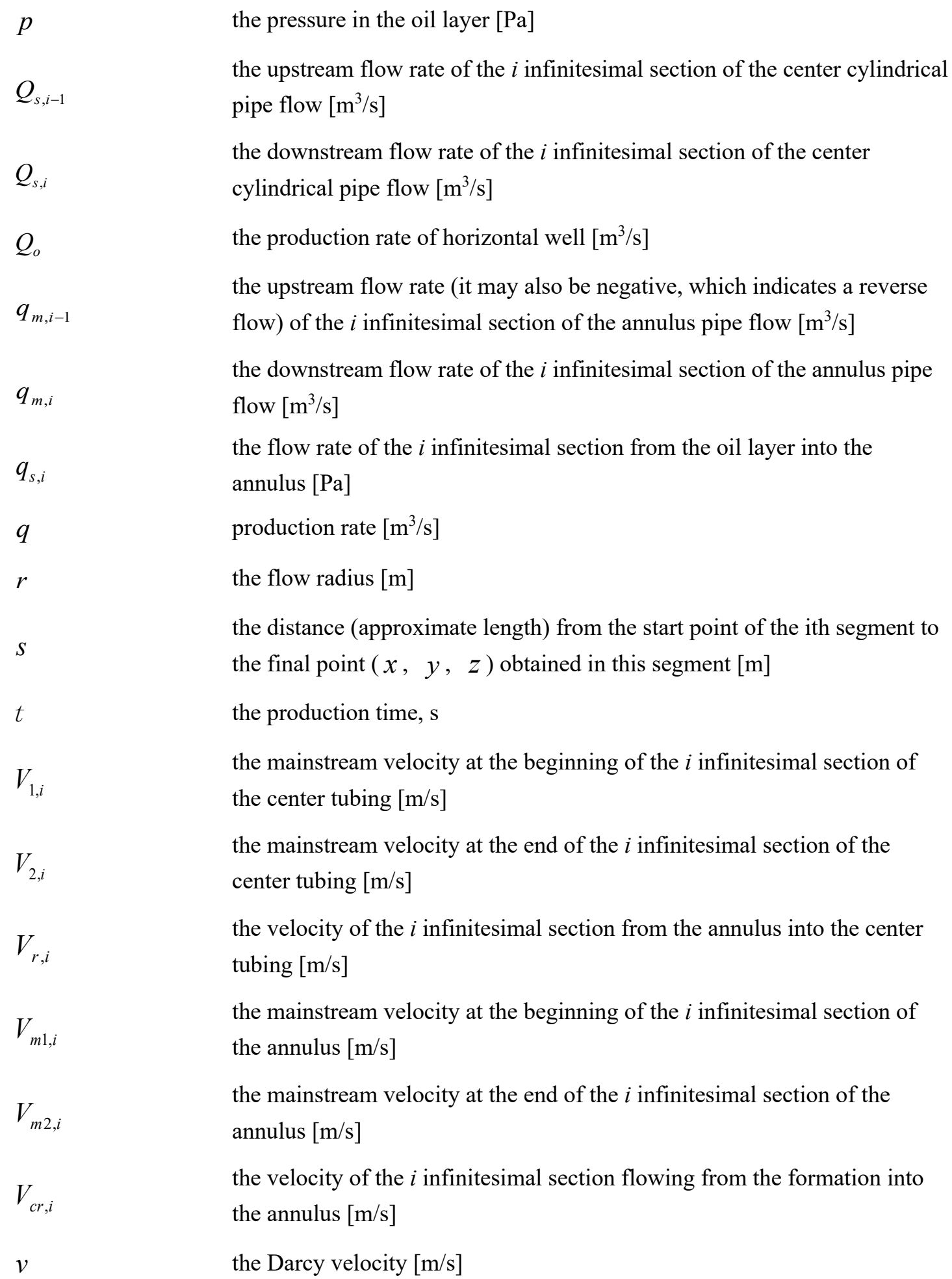




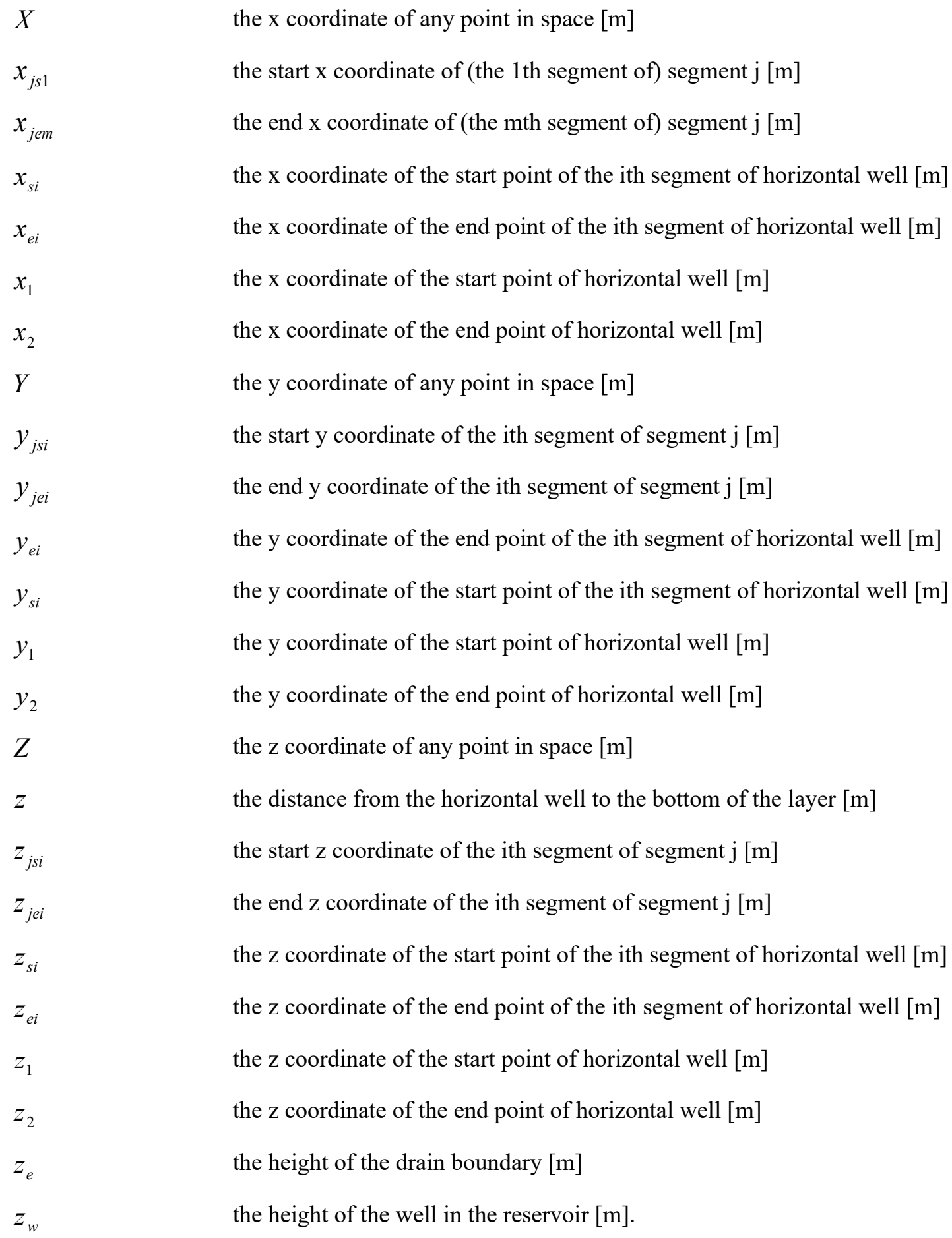

the $\mathrm{x}$ coordinate of any point in space $[\mathrm{m}]$

the start $\mathrm{x}$ coordinate of (the 1 th segment of) segment $\mathrm{j}[\mathrm{m}]$

the end $\mathrm{x}$ coordinate of (the mth segment of) segment $\mathrm{j}[\mathrm{m}]$

the $\mathrm{x}$ coordinate of the start point of the ith segment of horizontal well [m]

the $\mathrm{x}$ coordinate of the end point of the ith segment of horizontal well [m]

the $\mathrm{x}$ coordinate of the start point of horizontal well [m]

the $\mathrm{x}$ coordinate of the end point of horizontal well [m]

the $y$ coordinate of any point in space $[\mathrm{m}]$

the start y coordinate of the ith segment of segment $\mathrm{j}[\mathrm{m}]$

the end y coordinate of the ith segment of segment $\mathrm{j}[\mathrm{m}]$

the y coordinate of the end point of the ith segment of horizontal well [m]

the $y$ coordinate of the start point of the ith segment of horizontal well [m]

the y coordinate of the start point of horizontal well [m]

the $y$ coordinate of the end point of horizontal well [m]

the $\mathrm{z}$ coordinate of any point in space $[\mathrm{m}]$

the distance from the horizontal well to the bottom of the layer [m]

the start $\mathrm{z}$ coordinate of the ith segment of segment $\mathrm{j}[\mathrm{m}]$

the end $\mathrm{z}$ coordinate of the ith segment of segment $\mathrm{j}[\mathrm{m}]$

the $\mathrm{z}$ coordinate of the start point of the ith segment of horizontal well [m]

the $\mathrm{z}$ coordinate of the end point of the ith segment of horizontal well [m]

the $\mathrm{z}$ coordinate of the start point of horizontal well [m]

the $\mathrm{z}$ coordinate of the end point of horizontal well [m]

the height of the drain boundary $[\mathrm{m}]$

the height of the well in the reservoir [m].

Greek letters 


$$
\eta_{r}=\frac{k}{\mu \phi c_{t}}
$$

$\varphi_{j}$

$\phi_{e}$

$\phi_{j e}$

$\rho$

$\phi_{i j}$

$\partial V_{c}$

$\partial V$

$\partial s$

$\xi$

$\theta_{\text {i }}$

$\Delta q_{i}$

$\Delta p_{1, i}$

$\Delta p_{2, i}$

$\eta_{r}$ diffusion coefficient, $k$ permeability [mD], $\mu$ crude oil viscosity [mPa.s], $\phi$ Porosity [decimal], $c_{t}$ comprehensive formation compressibility [1/MPa]

The potential produced by well production

Viscosity [Pa.s]

The intermediate substitution function (equals to the formula within the outer layer braces of the formula (23))

the potential of the constant pressure boundary or the oil drainage boundary

the potential generated by the segment $\mathrm{j}$ at the constant pressure boundary or the oil drainage boundary

the density of the fluid $\left[\mathrm{kg} / \mathrm{m}^{3}\right]$

the potential generated by the $i$ segment line at the midpoint of the $j$ segment line

the micro-velocity variation in the micro-distance variation from the formation into the annulus $[\mathrm{m} / \mathrm{s}]$

the micro-velocity variation in the micro-distance variation from the annulus into the center tubing $[\mathrm{m} / \mathrm{s}]$

the micro-distance variation from the beginning of the $i$ infinitesimal section of the center tubing $[\mathrm{m}]$

The intermediate substitution function

the inclination angle from the horizontal plane of the $i$ infinitesimal section $\left[^{\circ}\right]$

the flow rate of the $i$ infinitesimal section from the annulus into the center tubing $[\mathrm{Pa}]$

the additional pressure drop between tubing and annulus at the beginning of the $i$ infinitesimal section under different completion modes [Pa]

the additional pressure drop between tubing and annulus at the end of the $i$ infinitesimal section under different completion modes [Pa] 
$\Delta s$

$a w$

$w$

The segment length [m].

\section{Subscript}

annulus wellbore

wellbore

the $i$ infinitesimal section (segment)

the friction loss of the center tubing

the acceleration loss of the center tubing

the mixing loss of the center tubing

the mixing loss of the annulus (middle)

the acceleration loss of the annulus (middle)

the mixed pressure drop loss of the annulus (middle)

horizontal

vertical

the $j$ infinitesimal section (segment)

the start of one segment of annulus

the end of one segment of annulus

the start of the $\mathrm{i}$ infinitesimal section (segment)

the end of the $\mathrm{i}$ infinitesimal section (segment)

the start of one segment of tubing

the end of one segment of tubing

the initial condition of the drain boundary

the bottom hole wellbore flow

sum of

tubing radial direction

casing radial direction 
jsi

jei the start of the ith segment of segment $j$

the end of the ith segment of segment $j$.

\section{INTRODUCTION}

Slotted screen completion and inflow control device (ICD) completion are two of the most common completions in horizontal well completion methods. Fluid flows from the oil reservoir into the wellbore through these completions, which result in additional pressure drop affecting the production rate of horizontal wells. However, prediction models for horizontal well production rate based on slotted screen and ICD completions have been simplified, such that only the flow in the center tubing is considered, while the flow in the annulus is disregarded (Alvarez, A. C. et al., 2014; Javid, K., 2018; Droppert, V., 2020; Gurses, S. F., 2013; Goh, G., 2016; Bol, L., 2016; Shahkarami, A., 2020; Eltazy, E., 2019; D Li, 2017). They all carried out the research on related models for ICD completion but did not consider the effects of annulus flow. Luo et al. (2015a, 2015b, 2017) presented a more detailed model for ICD completion than the previous ones but did not clearly analyze how annulus flow affects production rate through the flow rate profile and pressure drop profile along the center tubing and the annular wellbore. The flow in horizontal wells from the wellbore-annulus-reservoir processes of slotted screen completion and ICD completion is not considered. In this work, the authors have considered the wellbore-annulus-reservoir process in the horizontal section of slotted screen completion and ICD completion. A corresponding flow model, the newly established reservoir transient seepage model, and prediction model for the production rate of horizontal wells have been proposed. Further, the developed model is compared with existing models with and without annulus flow modeling.

\section{Physical Process of Fluid Flow in Slotted Screen Completion and ICD Completion}

Lorenz et al. (2006) conducted production simulations with and without ICD within an $8.53 \mathrm{~m}$ horizontal wellbore and compared the annular flow under the two conditions. Their experiments showed that, in the actual production, if the flow profile of the horizontal section is unevenly produced, the horizontal section of slotted screen completion and ICD completion will contain the variable mass flows of the center tubing and the annulus, as shown in Figure 1.

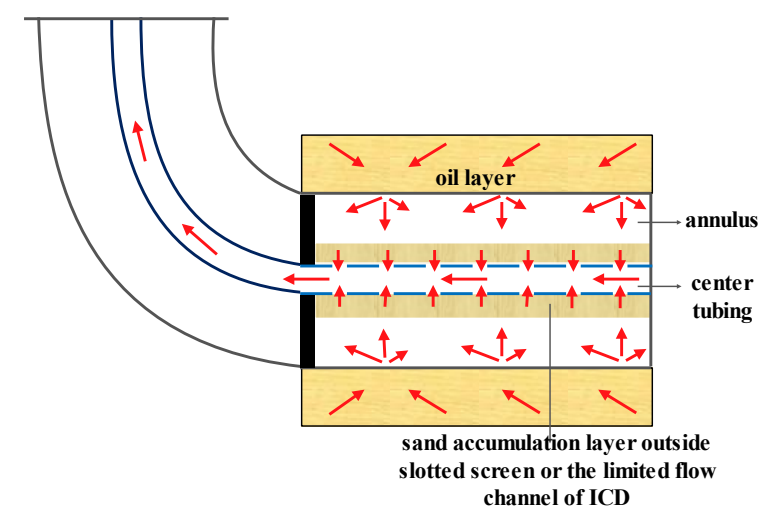

Figure 1. Diagram of horizontal well flow. 


\section{ESTABLISHMENT OF COUPLED MATHEMATICAL MODEL}

Horizontal well production involves two flow processes: the flow of fluid in the formation section and the flow of fluid in the wellbore section. In this study, models for fluid flow in the reservoir and in the wellbore are developed. The two models are then coupled to establish a prediction model for the production rate of horizontal wells.

\subsection{D instantaneous Darcy Flow Model in Consideration of the Real Wellbore Trajectory}

The 3D steady Darcy flow model in consideration of the real wellbore trajectory in this paper used the model in Luo et al. (2018). On this basis, according to the instantaneous point source function in space, the instantaneous formation seepage model is obtained as follows.

The 3D layer contains a horizontal well with length $L$ and productivity $q$, as shown in Figure 2 . The coordinates of the start and end parts are $\left(x_{1}, y_{1}, z_{1}\right)$ and $\left(x_{2}, y_{2}, z_{2}\right)$, respectively. We assumed the single-phase crude oil seepage in the formation, and the horizontal well was regarded as a line sink with a uniform inflow.

After dividing the horizontal well into $m$ parts on the average (the length of each part is $L / m$ ), the start coordinate of $i$ part is $\left({ }^{x_{s i}}, y_{s i}, z_{s i}\right)$, and the end coordinate is $\left({ }^{x_{e i}}, y_{e i}, z_{e i}\right)$. Additionally, $i=1,2,3$, ...m.

After obtaining a point in one sectional part with the coordinate $(x, y, z)$ as the final point, the length to the start point of this sectional part is

$$
s=\sqrt{\left(x-x_{s i}\right)^{2}+\left(y-y_{s i}\right)^{2}+\left(z-z_{s i}\right)^{2}}
$$
formula:

By obtaining the total differential of both sides of Formula (1), the infinitesimal part $d s$ meets the following

$$
d s=\frac{1}{s}\left[\left(x-x_{s i}\right) d x+\left(y-y_{s i}\right) d y+\left(z-z_{s i}\right) d z\right]
$$

For $d s$, the production of this part is $d q=\frac{q}{L} d s$. For the continuous point sink problem in space, the potential generated in space point $(X, Y, Z)$ is

$$
\mathrm{d} \phi=-\frac{\mathrm{d} q}{4 \pi r} \operatorname{erfc}\left(\frac{r}{2 \sqrt{\eta_{r} t}}\right)
$$


$\mathrm{d} \phi=-\frac{q}{4 \pi r L} \operatorname{erfc}\left(\frac{r}{2 \sqrt{\eta_{r} t}}\right) \mathrm{d} s$

$\mathrm{d} \phi=-\frac{q}{4 \pi r L} \operatorname{erfc}\left(\frac{r}{2 \sqrt{\eta_{r} t}}\right) \frac{1}{S}\left[\left(x-x_{s i}\right) \mathrm{d} x+\left(y-y_{s i}\right) \mathrm{d} y+\left(z-z_{s i}\right) \mathrm{d} z\right]$

We supposed that $f(x, y, z, t), g(x, y, z, t)$, and $h(x, y, z, t)$ are as follows:

$f(x, y, z, t)=-\frac{q}{4 \pi r L} \operatorname{erfc}\left(\frac{r}{2 \sqrt{\eta_{r} t}}\right) \frac{1}{s}\left(x-x_{s i}\right)$

$g(x, y, z, t)=-\frac{q}{4 \pi r L} \operatorname{erfc}\left(\frac{r}{2 \sqrt{\eta_{r} t}}\right) \frac{1}{s}\left(y-y_{s i}\right)$

$h(x, y, z, t)=-\frac{q}{4 \pi r L} \operatorname{erfc}\left(\frac{r}{2 \sqrt{\eta_{r} t}}\right) \frac{1}{s}\left(z-z_{s i}\right)$

Thus, as the spatial region belongs to $3 \mathrm{D}$ single connected open region $\mathrm{G}$, and $f(x, y, z, t)$, $g(x, y, z, t)$, and $h(x, y, z, t)$ have the first-order partial derivative in this region (for infinitesimals, $r$ and $\mathrm{t}$ are constants), the following formula is met:

$\frac{\partial f}{\partial y}=\frac{\partial g}{\partial x}, \quad \frac{\partial f}{\partial z}=\frac{\partial h}{\partial x}, \quad \frac{\partial g}{\partial z}=\frac{\partial h}{\partial y}$

The potential created by this part in space $(X, Y, Z)$ is

$\phi_{i}=\int_{\left(x_{s i}, y_{s i}, z_{s i}\right)}^{\left(x_{e i}, y_{e i}, z_{e i}\right)}-\frac{q}{4 \pi r L} \operatorname{erfc}\left(\frac{r}{2 \sqrt{\eta_{r} t}}\right) \mathrm{d} s+C$

$\phi_{i}=-\frac{q}{4 \pi L}\left(\int_{x_{s i}}^{x_{e i}} f\left(x, y_{s i}, z_{s i}, t\right) \mathrm{d} x+\int_{y_{s i}}^{y_{e i}} g\left(x, y, z_{s i}, t\right) \mathrm{d} y+\int_{z_{s i}}^{z_{e i}} h(x, y, z, t) \mathrm{d} z\right)+C$

Formula (11) can be rewritten as 


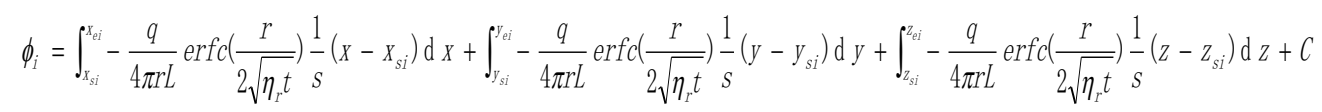

In the above formula, the first item on the right has $x$ as the integration variable. $y$ and $z$ are constant. The rest are integrated similarly.

The first item on the right is integrated as follows:

$$
\begin{aligned}
& \int_{x_{s i}}^{x_{e i}}-\frac{q}{4 \pi r L} \operatorname{erfc}\left(\frac{r}{2 \sqrt{\eta_{r} t}}\right) \frac{1}{S}\left(x-x_{s i}\right) \mathrm{d} x=-\frac{q}{4 \pi L} \int_{x_{s i}}^{x_{e i}} \frac{1}{r} \operatorname{erfc}\left(\frac{r}{2 \sqrt{\eta_{r} t}}\right) \frac{1}{s}\left(x-x_{s i}\right) \mathrm{d} x \\
& =-\frac{q}{4 \pi L} \int_{X_{s i}}^{x_{e i}}\left[\begin{array}{l}
\frac{1}{\sqrt{(x-X)^{2}+(y-Y)^{2}+(z-Z)^{2}}} \cdot \\
\frac{1}{2 \sqrt{\eta_{r} t}} \\
\frac{1}{\sqrt{\left(x-x_{S i}\right)^{2}+\left(y-y_{s i}\right)^{2}+\left(z-z_{S i}\right)^{2}}}\left(x-x_{S i}\right)
\end{array}\right] \mathrm{d} x
\end{aligned}
$$

After simplifying the formula and supposing that $a=(y-Y)^{2}+(z-Z)^{2}$,

$$
\begin{aligned}
& b=\left(y-y_{s i}\right)^{2}+\left(z-z_{s i}\right)^{2}, \\
& =-\frac{q}{4 \pi L} \int_{x_{s i}}^{x_{e i}} \frac{1}{\sqrt{(x-X)^{2}+a}} \operatorname{erfc}\left(\frac{\sqrt{(x-X)^{2}+a}}{2 \sqrt{\eta_{r} t}}\right) \frac{1}{\sqrt{\left(x-x_{s i}\right)^{2}+b}}\left(x-x_{s i}\right) \mathrm{d} x
\end{aligned}
$$

The formula can be

$$
f\left(x, y_{s i}, z_{s i}, t\right)=\frac{1}{\sqrt{(x-X)^{2}+a}} \operatorname{erfc}\left(\frac{\sqrt{(x-X)^{2}+a}}{2 \sqrt{\eta_{r} t}}\right) \frac{1}{\sqrt{\left(x-x_{s i}\right)^{2}+b}}\left(x-x_{s i}\right)
$$

Formula 3.1-32 equals the integration of $f\left(x, y_{s i}, z_{s i}\right)$ in the domain of $\left[x_{s i}, x_{e i}\right]$. 


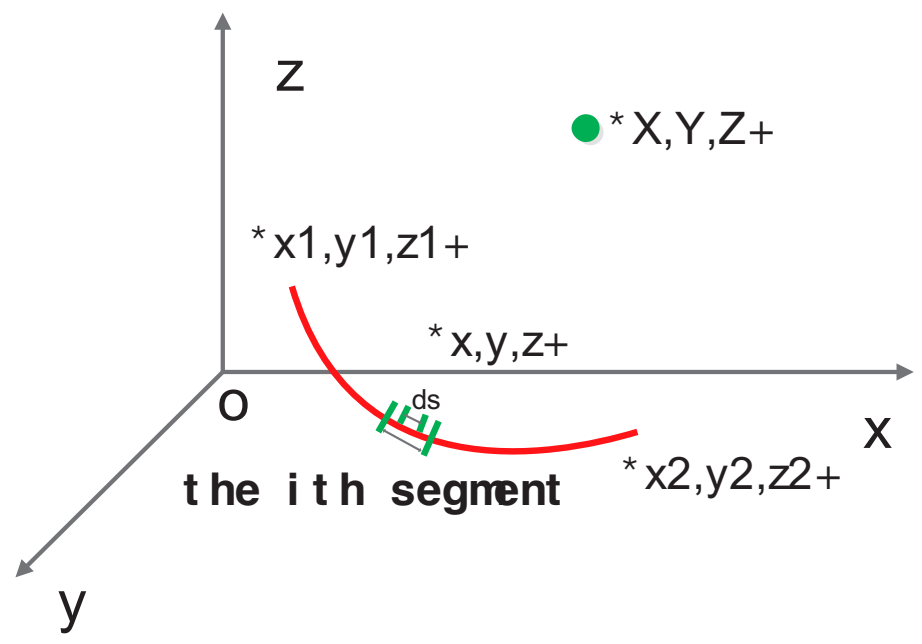

Figure 2. Schematic of horizontal wells in unbounded formation.

Finally, the entire potential in point $(X, Y, Z)$ from the horizontal well can be $\phi=\sum_{i=1}^{m} \phi_{i}=-\frac{q}{4 \pi L} \sum_{i=1}^{m}\left(\int_{X_{s i}}^{x_{e i}} f\left(x, y_{s i}, Z_{s i}, t\right) d x+\int_{y_{s i}}^{y_{e i}} g\left(x, y, z_{s i}, t\right) d y+\int_{z_{s i}}^{z_{e i}} h(x, y, z, t) d z\right)$

For different areas, the directions of the inflow from the edges present several differences with the inflow from the middle side. A mutual effect exists in interfacing parts, and the pressure drop appears. The flow rates of the different parts of the horizontal wellbore are different in the reservoir. Thus, the entire horizontal part is divided into many small parts because a small part is too short to be regarded as having a uniform flow. The potential generated by each part is equivalent to the potential of a horizontal well in formula (16). A top-closed reservoir with bottom water can be calculated by referring to the model used in Luo et al. (2018).

\section{Fluid Flow Model in the Wellbore Section}

(1) Computation model for flow rate and flow pressure of the infinitesimal section.

The length of the wellbore section is represented as $\mathrm{L}$ and is divided into $\mathrm{N}$ segments. Segment length is $\Delta s=L / N$ when sorting is conducted from toe to heel. The diagram of the $i$ infinitesimal section is provided in Figure 3.

In the $i$ infinitesimal section of the center cylindrical pipe flow, $p_{1, i}$ denotes upstream pressure, $Q_{s, i-1}$ denotes upstream flow rate, $p_{2, i}$ denotes downstream pressure, $Q_{s, i}$ denotes downstream flow rate, and $d p_{w, i}$ denotes the loss of pressure drop in the segment. 
In the $i$ infinitesimal section of the annulus pipe flow, $p_{\mathrm{a} 1, i}$ represents upstream pressure, $q_{m, i-1}$ represents upstream flow rate (it may also be negative, which indicates a reverse flow), $p_{a 2, i}$ represents downstream pressure, $q_{m, i}$ represents downstream flow rate, and $d p_{a w, i}$ represents the loss of annular pressure drop in the segment.

The following relationships are then derived:

$$
\begin{aligned}
& \Delta q_{i}=q_{s, i}+q_{m, i-1}-q_{m, i}, \\
& Q_{s, i}=Q_{s, i-1}+\Delta q_{i}, \\
& p_{1, i}=p_{2, i}+d p_{w, i}, \\
& p_{a 1, i}=p_{a 2, i}+d p_{a w, i}, \\
& p_{a 1, i}=p_{1, i}+\Delta p_{1, i}, \\
& p_{a 2, i}=p_{2, i}+\Delta p_{2, i}, \\
& \Delta p_{1, i}=\left.\Delta p\right|_{q=\frac{\Delta q_{i}+\Delta q_{i-1}}{2}} \\
& \Delta p_{2, i}=\left.\Delta p\right|_{q=\frac{\Delta q_{i}+\Delta q_{i+1}}{2}}
\end{aligned}
$$

In the preceding formulae, $\Delta q_{i}$ indicates the flow rate of the $i$ infinitesimal section from the annulus into the center tubing, $q_{s, i}$ indicates the flow rate of the $i$ infinitesimal section from the oil layer into the annulus, $\Delta p_{1, i}$ indicates the additional pressure drop between tubing and annulus at the beginning of the $i$ infinitesimal section under different completion modes, and $\Delta p_{2, i}$ indicates the additional pressure drop between tubing and annulus at the end of the $i$ infinitesimal section under different completion modes. For slotted screen completion, the details are provided in Xiong et al. (1997). The ICD completion uses spiral channel-type ICD (Zhang, 2013). 


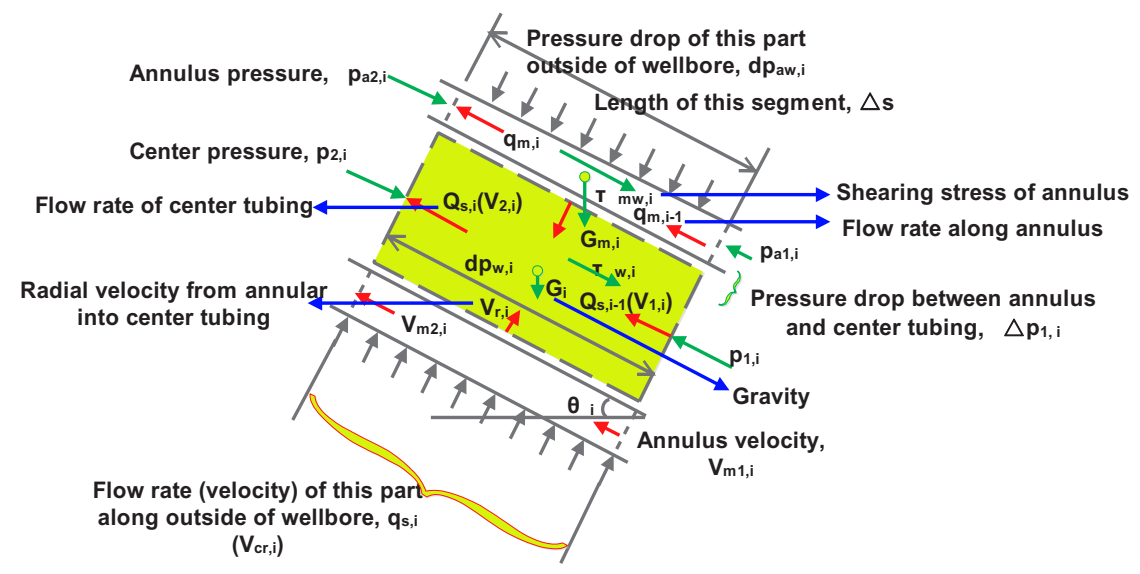

Figure 3. Flow diagram and force analysis of the $i$ infinitesimal section.

Flow pressure in the center cylinder of the $i$ infinitesimal section considers the average value of pressure in the following section:

$p_{w, i}=\frac{p_{1, i}+p_{2, i}}{2} \quad(i=1,2, \ldots, \mathrm{N})$.

Pressure in the annulus of the $i$ infinitesimal section considers the average value of the following section pressure:

$p_{a w, i}=\frac{p_{a 1, i}+p_{a 2, i}}{2}(i=1,2, \ldots, \mathrm{N})$.

Assuming that no initial flow is observed at the toe of the wellbore, $Q_{s, 0}=0$. Thus, the flow pressure at the end of the horizontal section is equal to the bottom hole flow pressure $p_{w f}$. Accordingly, the following equation is applied:

$p_{w f}=p_{w, N}+\frac{1}{2} d p_{w, N}$.

(2) Calculation model for pressure-loss $d p_{w, i}$ in the $i$ infinitesimal section

Pressure loss in the center cylinder of the $i$ infinitesimal section includes gravity loss, friction loss, acceleration loss, and mixing loss. Assume that $d p_{f, i}$ is the friction loss in the $i$ infinitesimal section $(\mathrm{Pa})$, $d p_{a c c, i}$ is the acceleration loss $(\mathrm{Pa})$, and $d p_{\text {mix }, i}$ is the mixing loss $(\mathrm{Pa})$. The value of the mixing loss is zero (0) in this study. In accordance with the principle of conservation of mass (Liu et al., 1999),

$\rho V_{1, i} \frac{\pi D^{2}}{4}+\rho V_{r, i} \pi D d s-\rho\left(V_{1, i}+\frac{\partial V}{\partial s} d s\right) \frac{\pi D^{2}}{4}=0$. 
The following equation can be derived (Indicating the increase in flow velocity in the unit length of the tube):

$$
\frac{\partial V}{\partial s}=\frac{4 V_{r, i}}{D}
$$

where $\rho$ is the density of the fluid $\left(\mathrm{kg} / \mathrm{m}^{3}\right), D$ is the diameter of the center tubing $(\mathrm{m}), V_{1, i}$ is the mainstream velocity at the beginning of the $i$ infinitesimal section of the center tubing $(\mathrm{m} / \mathrm{s}), V_{r, i}^{1, i}$ is the velocity of the $i$ infinitesimal section from the annulus into the center tubing $(\mathrm{m} / \mathrm{s}), \partial V$ is the micro-velocity variation in the micro-distance variation from the annulus into the center tubing $(\mathrm{m} / \mathrm{s})$, and $\partial s$ is the micro-distance variation from the beginning of the $i$ infinitesimal section of the center tubing $(\mathrm{m})$.

Annular pressure loss in the $i$ infinitesimal section includes gravity loss, friction loss, acceleration loss, and mixing loss. Assume that $d p_{m f, i}$ is the friction loss in the $i$ infinitesimal section $(\mathrm{Pa}), d p_{\text {macc, } i}$ is the acceleration loss $(\mathrm{Pa})$, and $d p_{m m i x, i}$ is the mixing loss $(\mathrm{Pa})$. During the flow process, due to the continuous flow of fluid in the lateral direction, the total flow gradually increases. For a certain unit length, in accordance with the principle of conservation of mass, the following equation can be derived:

$$
\begin{aligned}
& \rho V_{m 1, i} \frac{\pi\left(D_{c}^{2}-D^{2}\right)}{4}+\rho V_{c r, i} \pi D_{c} d s-\rho V_{r, i} \pi D d s- \\
& {\left[\rho\left(V_{m 1, i}+\frac{\partial V_{c}}{\partial s} d s\right) \frac{\pi\left(D_{c}^{2}-D^{2}\right)}{4}-\rho \frac{\partial V}{\partial s} d s \frac{\pi D^{2}}{4}\right]=0}
\end{aligned}
$$

When the preceding equation is combined with the mass conservation formulas of the center tubing, we obtain (indicating the increment of velocity in the annulus per unit length)

$$
\frac{\partial V_{c}}{\partial s}=\frac{4 V_{c r, i} D_{c}}{D_{c}^{2}-D^{2}}
$$

where $V_{m 1, i}$ is the mainstream velocity at the beginning of the $i$ infinitesimal section of the annulus (m/s), $V_{c r, i}$ is the velocity of the $i$ infinitesimal section flowing from the formation into the annulus $(\mathrm{m} / \mathrm{s}), D_{c}$ is the internal diameter of the casings $(\mathrm{m})$, and $\partial V_{c}$ is the micro-velocity variation in the micro-distance variation from the formation into the annulus $(\mathrm{m} / \mathrm{s})$.

As shown in Figure 3, and based on the principle of momentum conservation, the total pressure drop loss includes the loss of the gravity term (if any), the loss of the friction term, and the loss of the acceleration term, and the calculation of the total pressure loss in the center $d p_{w, i}$ is

$$
-\frac{d p_{w, i}}{d s}=\rho g \sin \theta_{i}+\frac{f_{f, i} \rho}{2 D}\left(\frac{V_{1, i}+V_{2, i}}{2}\right)^{2}+\frac{8 \rho V_{1, i} V_{r, i}}{D}+\frac{16 \rho V_{r, i}^{2}}{D^{2}} d s+\frac{d p_{m i x, i}}{d s}
$$

where $g$ is the acceleration due to gravity $\left(\mathrm{m} / \mathrm{s}^{2}\right), \theta_{\mathrm{i}}$ is the inclination angle from the horizontal plane of the $i$ infinitesimal section $\left(^{\circ}\right)$, and $f_{f, i}$ is the frictional factor (in this paper, single-phase flow is assumed. In case of oil-gas two-phase flow or oil-gas-water three-phase flow, the wall friction coefficient is calculated by 
multiphase pipe flow calculation method (Beggs and Brill method), and the flow pattern of gas-liquid velocity is predicted by Beggs and Brill method), $V_{2, i}$ is the mainstream velocity at the end of the $i$ infinitesimal section of the center tubing, and $d s$ is the length of the $i$ infinitesimal section that is equal to $\Delta s(\mathrm{~m})$.

In accordance with the principle of momentum conservation, the total pressure drop loss in the annulus also includes the loss of the gravity term (if any), the loss of the friction term, and the loss of the acceleration term, and the calculation of total annular pressure loss $d p_{m, i}$ is obtained as

$-\frac{d p_{a W, i}}{d s}=\rho g \sin \theta_{i}+\frac{f_{m f, i} \rho}{2 \bar{D}}\left(\frac{V_{m 1, i}+V_{m 2 . i}}{2}\right)^{2}+\rho \frac{V_{m 2, i}^{2}-V_{m 1, i}^{2}}{d s}+\frac{d p_{m m i x, i}}{d s}$

In the preceding formulas, $d p_{a w, i}$ denotes the annulus pressure drop in the $i$ infinitesimal section (Pa),

$\bar{D}$ denotes the equivalent diameter of the annulus (i.e., area equivalent) (m), and $f_{m f, i}$ denotes the friction factor of the annular area (in this paper, single-phase flow is assumed). In case of oil-gas two-phase flow or oil-gas-water three-phase flow, the wall friction coefficient is calculated by multiphase pipe flow calculation method (Beggs and Brill method), and the flow pattern of gas-liquid velocity is predicted by Beggs and Brill method), $V_{m 2, i}$ is the mainstream velocity at the end of the $i$ infinitesimal section of the annulus (m/s), and $d p_{m m i x, i}$ is the mixed pressure drop loss $(\mathrm{Pa})$. The values of the mixed pressure drop in this study are 0.

\section{Transient Coupling and its Solution}

Assume that $p_{w, j}$ is the pressure at the midpoint of the center of the $j$ section of the horizontal well. The pressure at the midpoint of the annulus in the $j$ section is

$p_{\mathrm{a} w, j}=p_{w, j}+\frac{\Delta p_{1, j}+\Delta p_{2, j}}{2}$.

Assuming that $\phi_{i j}$ is the potential generated by the $i$ segment line at the midpoint of the $j$ segment line, according to the superposition principle of potential and the corresponding relationship between pressure and potential (Luo et al., 2018), we obtain

$p_{a w, j}=p_{e}+\frac{\mu}{k} \sum_{i=1}^{N}\left(\phi_{i j}-\phi_{i e}\right)+\rho g\left(z_{e}-z_{w}\right)(j=1,2, \ldots, \quad \mathrm{N})$, 
where $p_{e}$ is the formation pressure of the drain boundary (Pa), $\mu$ is the fluid viscosity (Pa.s), $k$ is the permeability $\left(\mathrm{m}^{2}\right), z_{e}$ is the height of the drain boundary $(\mathrm{m})$, and $z_{w}$ is the height of the well in the reservoir (m).

The preceding formula is then rearranged as follows (Luo et al., 2018):

$\sum_{i=1}^{N} \lambda q_{s, i}\left(\varphi_{i j}-\varphi_{i e}\right)=p_{e}-p_{\mathrm{a} w, j}+\rho g\left(z_{e}-z_{w}\right)(j=1,2, \ldots, \mathrm{N})$

where $\lambda=\frac{\mu}{4 \pi k}$.

The pressure drop in the center tubing can be calculated using Eq. 36. The pressure at the midpoint of section $j$ of the center tubing is

$p_{w, j}=p_{1, j}-0.5 d p_{w, j}(j=1,2, \ldots, \mathrm{N})$.

From Eq. 37, $p_{2, N}=p_{w f}$, and $p_{w f}$ is the heel end pressure of the wellbore.

$p_{1, j+1}=p_{2, j}=p_{1, j}-d p_{w, j}(j=1,2, \ldots, \mathrm{N})$

The total well output is

$Q_{o}=\frac{\left(q_{s, 1}+q_{s, 2}+q_{s, 3}+\cdots+q_{s, N}\right)}{B_{o}}$,

where $B_{o}$ is the volume factor of crude oil, and $Q_{o}$ is the production rate of horizontal well.

In the coupled model, $q$ and $p_{\text {aw }}$ are unknown but can be determined by using an iterative method. Suppose that a group of $p_{\text {aw }}$ values and solutions with Eq. 36 is available to obtain the numerical value of $q$. Then, $q$ is substituted into pressure drop Eq. 23, 24, 32, 34, and 37. $p_{\mathrm{a} w}$ is updated from the heel to the toe, and the value of $q$ is updated using Eq. 36. These procedures are repeated until $p_{\mathrm{a} w}$ and $\mathrm{q}$ reach the desired accuracy. When the error between the output of each section this time and the output of each section corresponding to the last calculation is less than $0.01 \mathrm{~m}^{3} / \mathrm{d}$, the iteration is ended. Finally, Eq. 39 is used to obtain the output for the whole well. The specific calculation flow chart is shown in Figure 4. 


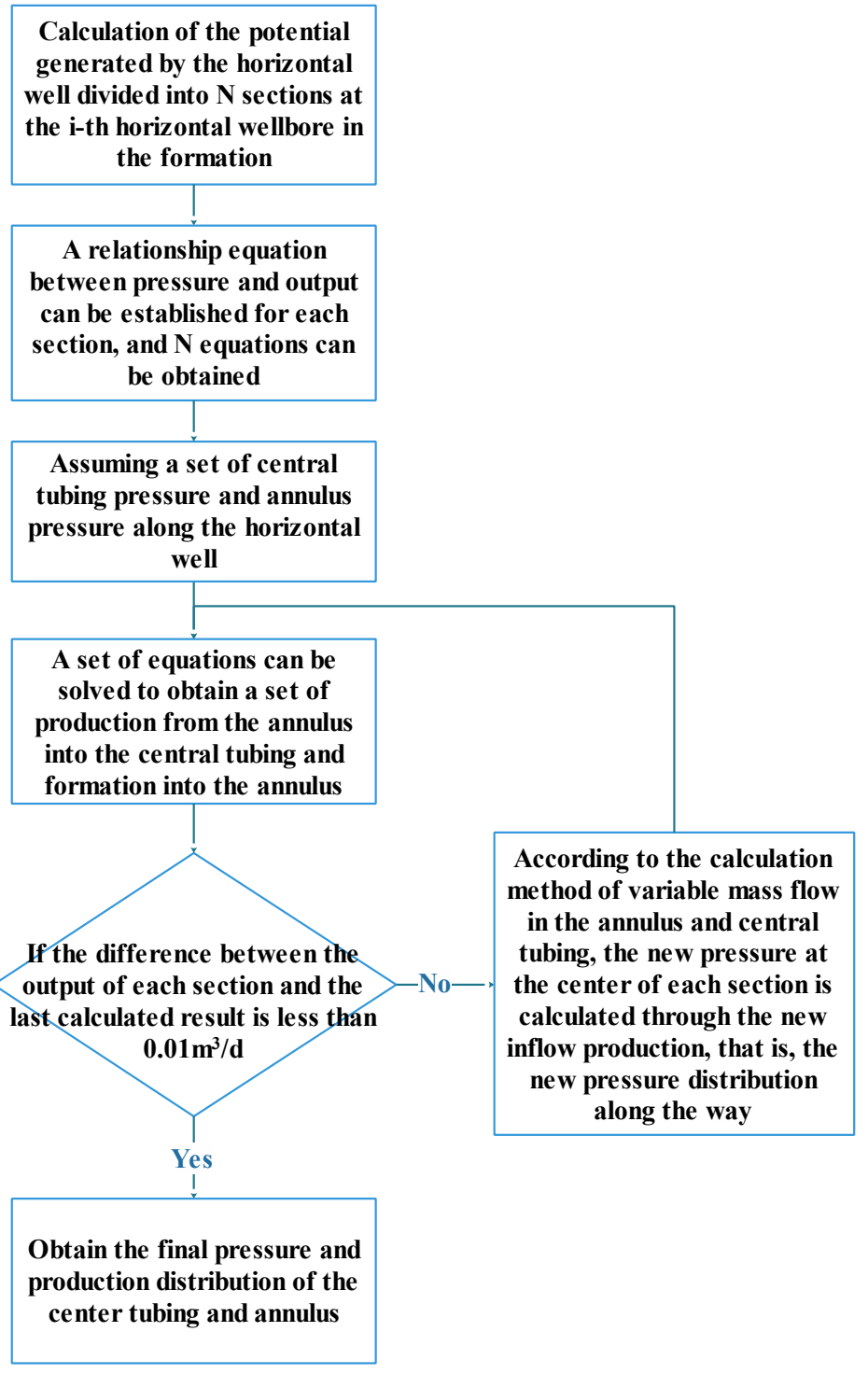

Figure 4. The calculation flow chart.

\section{SAMPLE CALCULATION AND VERIFICATION}

Well no. XXX-1 in the reservoir of the Halfaya Oilfield with bottom water in Iraq is selected as an example, as shown in Table 1. Slotted screen completion and ICD completion are simulated using the model established in this study and the simulation software from the Computer Modeling Group Ltd. (CMG; Alberta, Canada) with and without considering the simulation of annulus flow conditions. 
Table 1. Basic data of Well XXX-1.

\begin{tabular}{|c|c|c|}
\hline Parameters & Value & Unit \\
\hline Original horizontal permeability & 13.4 & $\mathrm{mD}$ \\
\hline Original vertical permeability & 1.34 & $\mathrm{mD}$ \\
\hline Hole diameter & 0.149 & $\mathrm{~m}$ \\
\hline Viscosity of crude oil & 1.62 & mPa.s \\
\hline Volume factor of crude oil & 1.35 & \\
\hline Eccentricity & 0 & $\mathrm{~m}$ \\
\hline Drainage radius & 457.2 & $\mathrm{~m}$ \\
\hline Length of horizontal well & 600 & $\mathrm{~m}$ \\
\hline Reservoir thickness & 30 & $\mathrm{~m}$ \\
\hline Density of crude oil & 0.794 & $\mathrm{~g} / \mathrm{cm}^{3}$ \\
\hline Formation pressure & 31.13 & $\mathrm{MPa}$ \\
\hline Absolute open flow potential & 1357.5 & $\mathrm{~m}^{3} / \mathrm{d}$ \\
\hline
\end{tabular}

\section{Calculation and Comparison of the Example with Slotted Screen Completion with and without Considering Annulus Flow}

The parameters of slotted screen completion are as follows: the outside diameter of the screen is $114.3 \mathrm{~mm}$ with 120 holes per meter. Hole diameter is $10 \mathrm{~mm}$, and holes are uniformly distributed. A thin layer of filter sleeve is placed outside the screen. The well test showed that the screen has an evident sand layer. The permeability of the sand layer is $14,000 \mathrm{mD}$ based on the absolute open flow potential of the oil well. Assume that no packer is placed outside the screen and that the bottom hole pressure is $0 \mathrm{MPa}$ in the heel. Horizontal well pressure profiles and liquid production profiles (the point of the production rate is the total rate of $10 \mathrm{~m} \mathrm{long}$ ) are shown in Figs. 5 and 6 , with and without considering annulus flow when the production is stable in the initial production stage. The total output and the predicted increase range by model without annulus flow modeling are shown in Table 2. 
The information presented in the graphs (Figs. 5 and 6) and Table 2 shows that the prediction of the model without annulus flow modeling is $9.51 \%$ higher than that of the model with annulus flow modeling and that the pressure values of the borehole wall and the flow profile are more uniform in the model with annulus flow modeling. The error between the two flow models will be reduced if an appropriate number of packers are placed outside the pipe. The results of the flow profile of the center tubing calculated using the model with annulus flow modeling clearly show a flow in the annulus from the toe to the heel to aggregate flow into the center tubing.

On the basis of reservoir, fluid, and oil well parameters, simulation mechanism models for wellbore flow with and without annulus flow are established using the CMG FlexWell function. The screen hole flow of screen completion is simulated using the ICD Orifice model because their flows are similar. The grid size is $92 \times 92 \times 3 \mathrm{~m}^{3}$, and each grid is $10 \mathrm{~m}$. The horizontal well is located in the middle level of the grid, and its length is $600 \mathrm{~m}$. In addition, the values of other parameters (such as the diameter of the well) are the same as the values of the corresponding parameters in the example in Table 1. The open hole place of the pipe string is located in the middle of each grid, and thus, the distance between the front and rear holes is $580 \mathrm{~m}$. Hole size and the number of ICD orifices are the same as those in screen completion. The model is shown in Figures 7 and 8.

Figure 5 and Figure 6 present the simulation results of different CMG models when the production is stable in the initial production stage. The figures also show that the simulation results (profiles of pressure and production) of the flow model without annulus flow are consistent with the simulation results of the new corresponding model when the well production rate is $1332 \mathrm{~m}^{3} / \mathrm{d}$, which is the same as the production rate of the model established in this study (Table 2). The simulation results (well production is shown in Table 2) for the wellbore flow model with annular flow are also consistent with the simulation results of the new corresponding model in Figure 5 and Figure 6. The CMG simulator can simulate the flow from the annulus into the tubing. The flow rule along the center tubing in the simulation results can reflect the authenticity of the simulation results of the established model from the annulus wellbore, which is also consistent with the results of this study.

Table 2. Production predicted by the two models.

\begin{tabular}{|c|c|c|c|}
\hline Simulator & $\begin{array}{c}\text { Model with annulus } \\
\text { flow modeling } \\
\mathrm{m}^{3} / \mathrm{d}\end{array}$ & $\begin{array}{c}\text { Model without } \\
\text { annulus flow } \\
\text { modeling } \\
\mathrm{m}^{3} / \mathrm{d}\end{array}$ & $\begin{array}{c}\text { The predicted } \\
\text { increase range of } \\
\text { model without } \\
\text { annulus flow } \\
\text { modeling } \%\end{array}$ \\
\hline New model & 1217.35 & 1333.06 & 9.51 \\
\hline CMG & 1217 & 1332 & \\
\hline
\end{tabular}




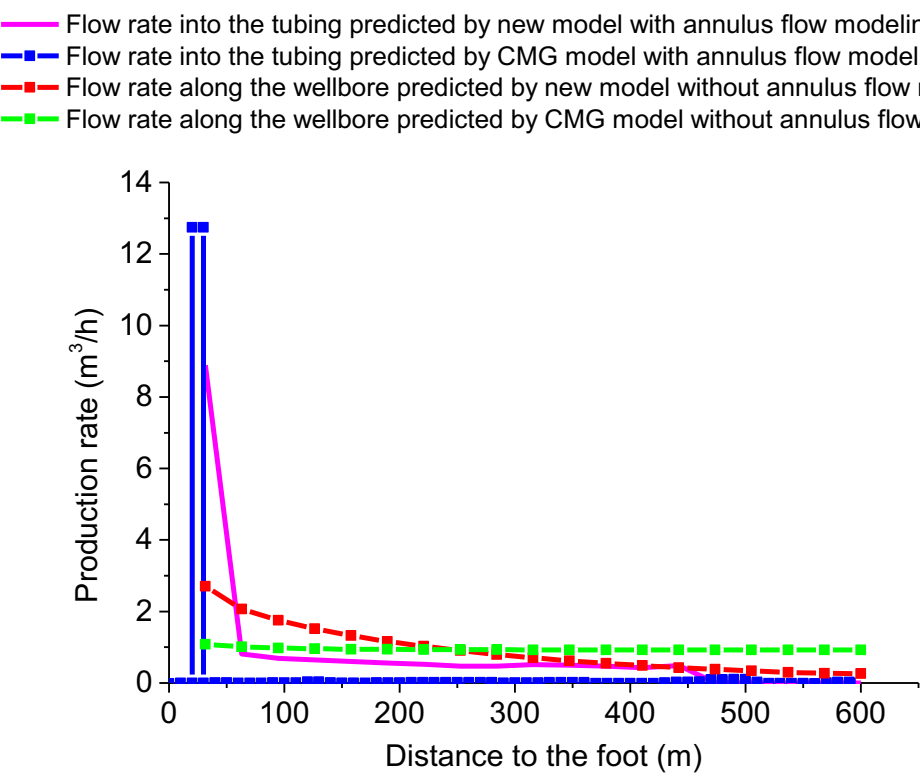

Figure 5. Profiles of production flowing into the tubing (or along the wellbore) are calculated using the two flow models for slotted screen in the new model and the CMG simulator.
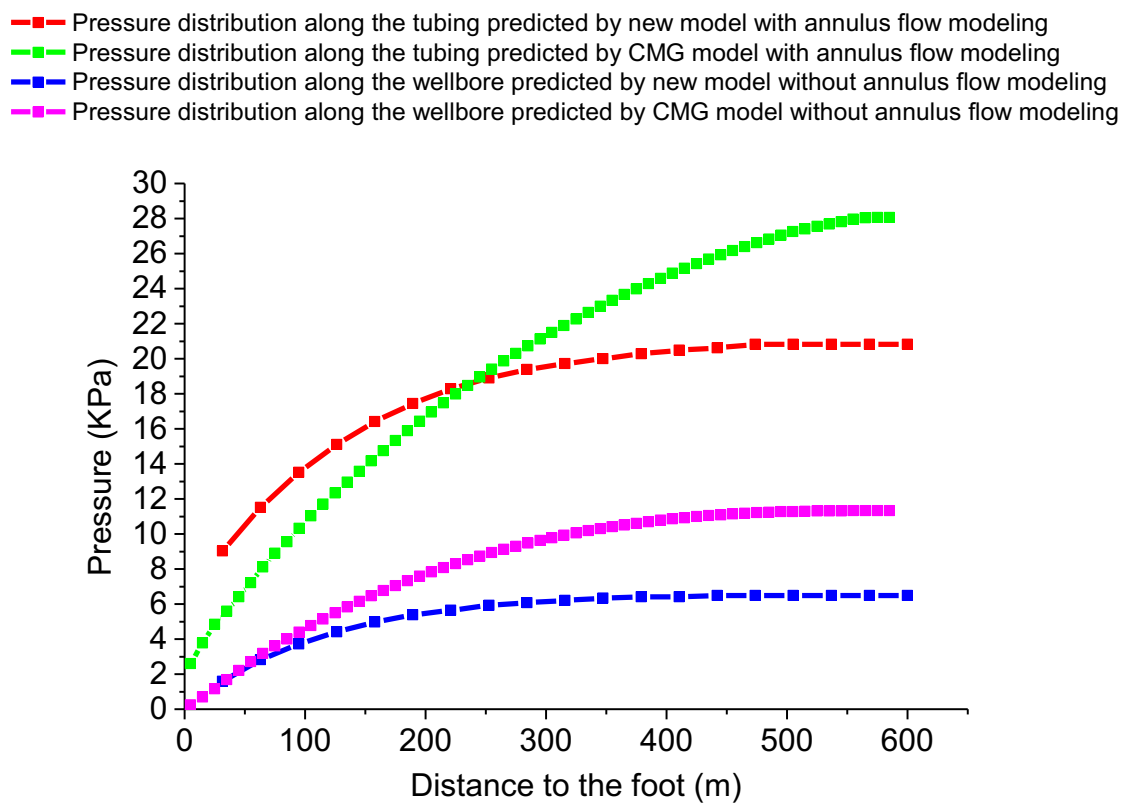

Figure 6. Profiles of pressure flowing along the borehole are calculated using the two flow models for slotted screen in the new model and the CMG simulator. 
324 Flow simulation for a horizontal well with slotted screen and ICD completions based on the wellbore-annulus-transient seepage reservoir model

Grid Top (m) 2017-01-01

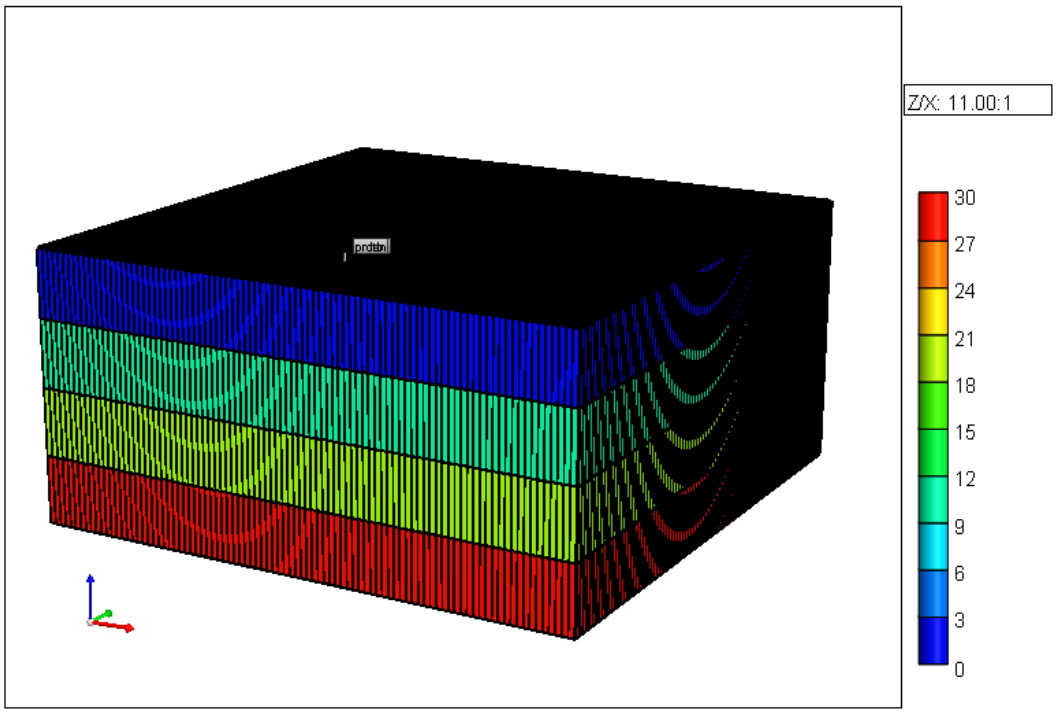

Figure 7. Stereoscopic grid model.

Grid Top (m) 2017-01-01 K layer: 2

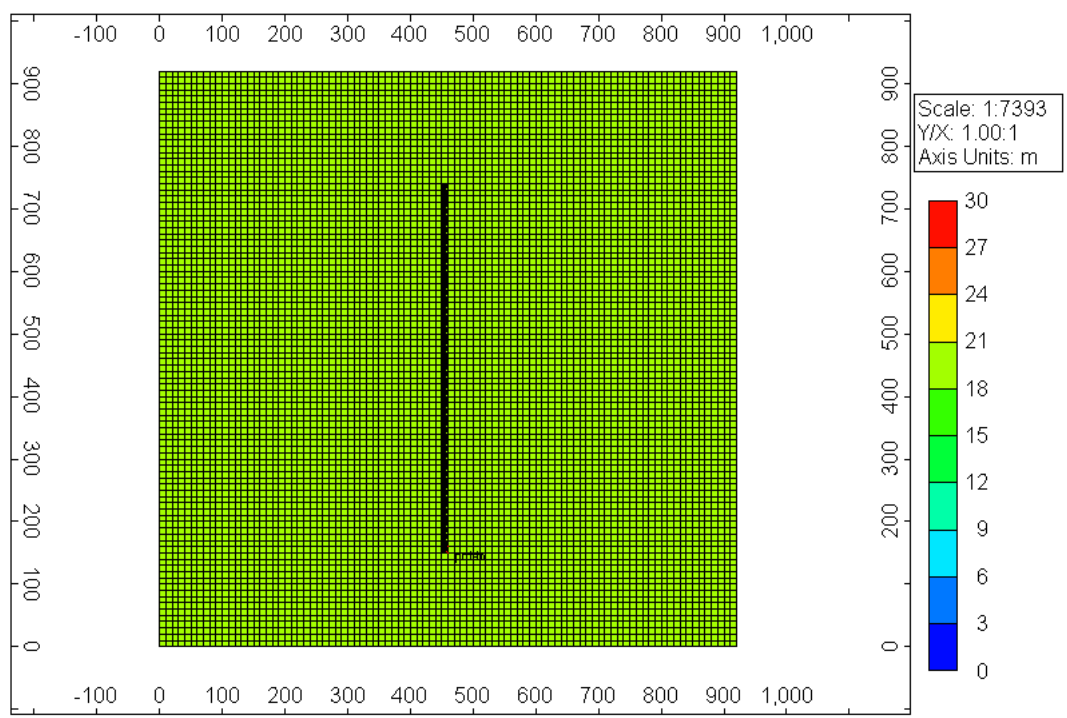

Figure 8. Plane grid model of the well and middle horizons. 


\section{Calculation and Comparison of the Example with ICD Completion with and without Considering Annulus Flow}

Assuming that the well is completed with ICD and that no sand has accumulated outside the pipe, the ICD completion parameters are as follows: the outside diameter of the ICD is $114.3 \mathrm{~mm}$, the length (throttling device) of a single throttle pipe is $2 \mathrm{~m}$, the diameter of the throttle pipe is $3 \mathrm{~mm}$, and the local head loss factor is 0.16 . Further, assuming that the entire horizontal section of the ICD is arranged, the ICD pipe has no packer, and the bottom hole pressure is $0 \mathrm{MPa}$ in the heel, the horizontal well pressure profiles and liquid production profiles are shown in Figs. 9 and 10, with and without considering annulus flow. The total output and the predicted increase range by model without annulus flow modeling are presented in Table 3.

The information presented in the graphs (Figs. 9 and 10) and Table 3 shows that, in the prediction of ICD well completion, the result of the model without annulus flow modeling is $70.98 \%$ higher than that of the model with annulus flow modeling. Moreover, the pressure and flow profiles along the borehole wall are more uniform. Although the calculation example assumes that no packer is placed outside the tube, and the predicted increase range of the predicted production between the two models is considerable, the real completion pipe with a certain number of packers reduces only the error between the models with and without annulus flow modeling prediction results. When the out-of-pipe packer condition is considered, the error between the models with and without annulus flow modeling can still be significant. The specific error is related to the number and positions of packers outside the pipe. Further research can be conducted based on the model with annulus flow modeling. The results of the flow profile of the center tubing calculated using the ICD model with annulus flow modeling also show a clear flow in the annulus from the toe to the heel to aggregate flow into the center tubing.

Table 3. Production predicted by the two models.

\begin{tabular}{|c|c|c|c|}
\hline Simulator & $\begin{array}{c}\text { Model with annulus } \\
\text { flow modeling } \\
\mathrm{m}^{3} / \mathrm{d}\end{array}$ & $\begin{array}{c}\text { Model without annulus } \\
\text { flow modeling } \\
\mathrm{m}^{3} / \mathrm{d}\end{array}$ & $\begin{array}{c}\text { The predicted } \\
\text { increase range of } \\
\text { model without } \\
\text { annulus flow } \\
\text { modeling } \%\end{array}$ \\
\hline New model & 874.92 & 1495.93 & 70.98 \\
\hline CMG 1 & 870.1 & 1482 & \\
\hline CMG 2 & 870.7 & $\begin{array}{c}1482 \text { (using the same } \\
\text { results as the above row) }\end{array}$ & \\
\hline CMG 3 & 872.9 & $\begin{array}{c}1482 \text { (using the same } \\
\text { results as the above row) }\end{array}$ & \\
\hline
\end{tabular}




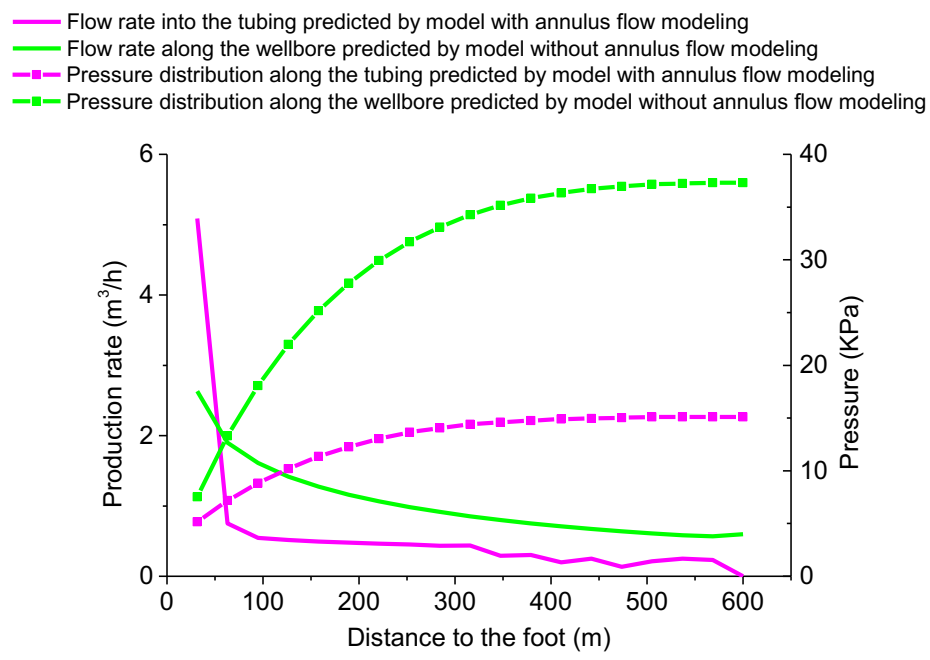

Figure 9. Profiles of pressure distribution and flow into the tubing (or along the wellbore) are calculated using the two flow models for ICD.

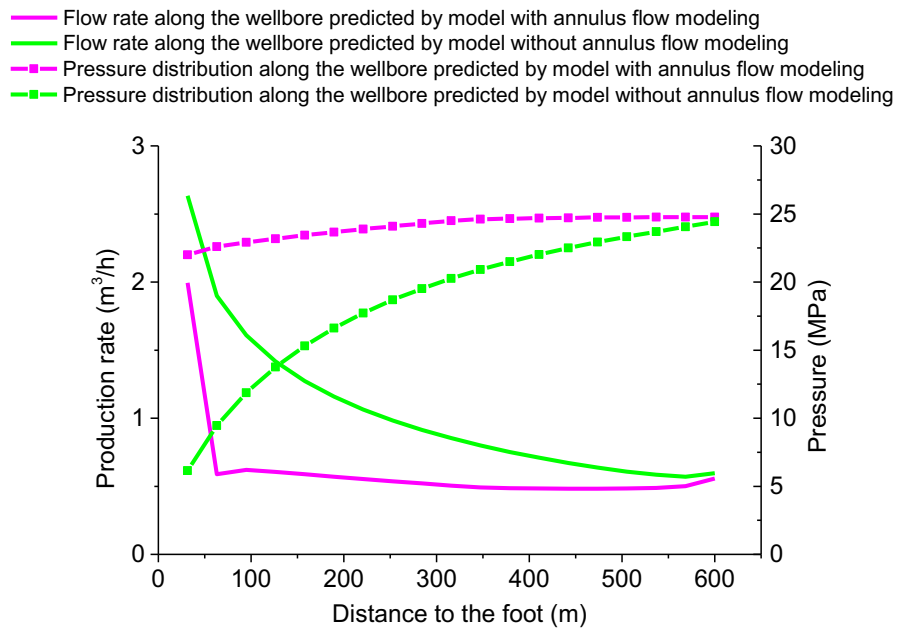

Figure 10. Profiles of pressure distribution and flow along the borehole are calculated using the flow models for ICD.

Similarly, the mechanism models with and without annular flow are established via CMG FlexWell function according to the parameters of reservoir, fluid, and oil well. The ICD Orifice model is also used to simulate ICD friction pressure drop. The ICD friction pressure drop model is also adopted in CMG simulation. Despite the easy flow conditions, the simulation produces no results for production. Therefore, only the ICD Orifice model can be used for the simulation. The hole size and number of ICD orifices are the same as those in ICD friction. The 
pressure drop-type completion (throttling device) and the flow that corresponds to the flow of ICD friction pressure drop-type completion can be adjusted by setting the diffusion coefficient.

Figures 11, 12, and 13 illustrate the simulation results of the different CMG models when the production is stable. The simulation results of the flow model without annulus flow (well production is shown in Table 3) are consistent with the simulation results of the corresponding model in Figure 8. The simulation results (well production is shown in Table 3) of the wellbore flow model with annular flow are also consistent with the simulation results of the corresponding model.

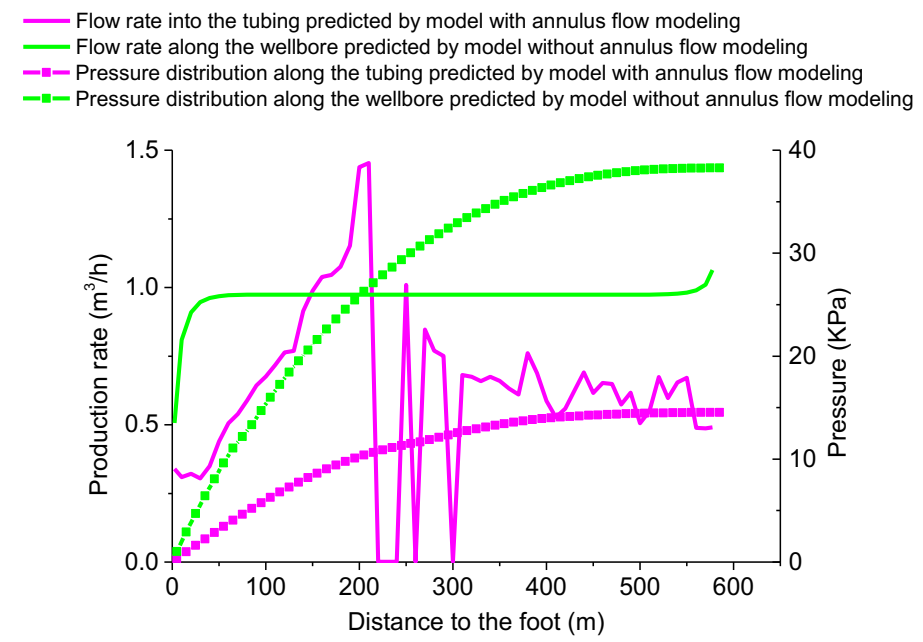

Figure 11. Profiles of pressure distribution and flow into the tubing (or along the wellbore) for the first case calculated using the two flow models for ICD in the CMG simulator.

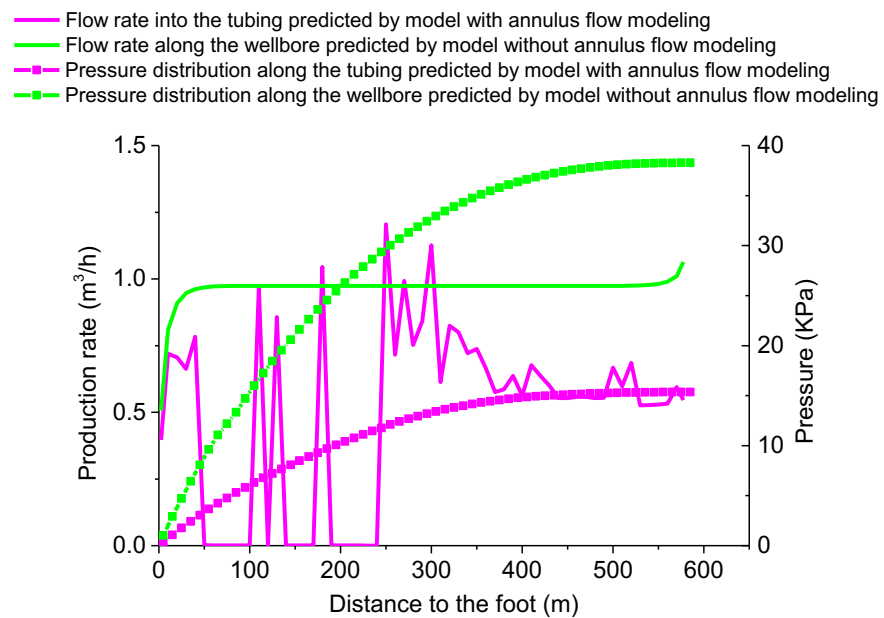

Figure 12. Profiles of pressure distribution and flow into the tubing (or along the wellbore) for the second case calculated using the two flow models for ICD in the CMG simulator. 


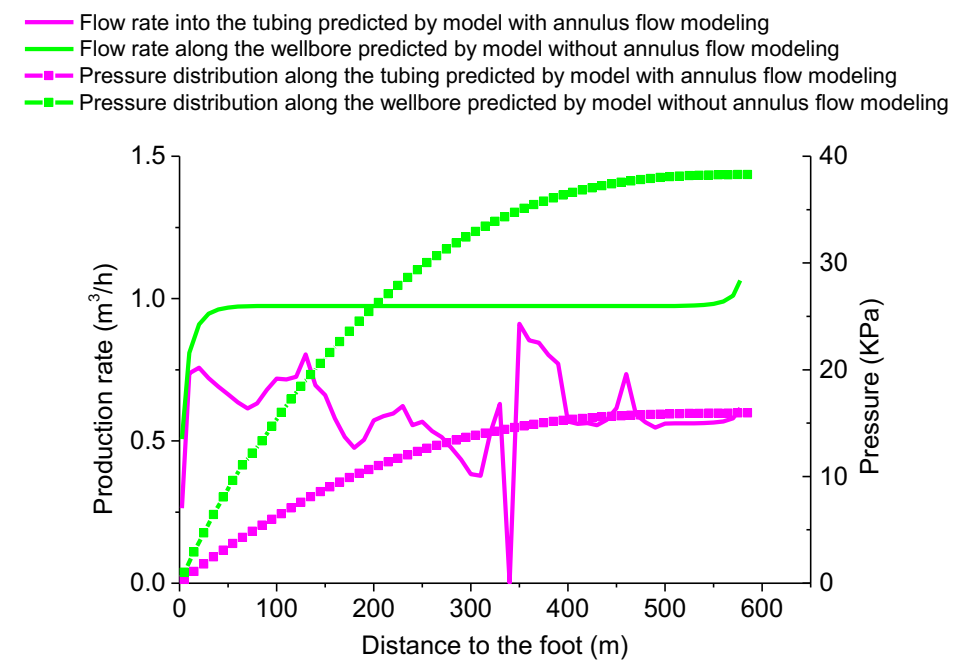

Figure 13. Profiles of pressure distribution and flow into the tubing (or along the wellbore) for the third case calculated using the two flow models for ICD in the CMG simulator.

\section{CONCLUSION}

Flow models for slotted screen and ICD completions have been established by considering annulus flow. Based on the newly established formation transient seepage model and wellbore and annulus variable mass flow model, an accurate prediction of the production rate of a horizontal well and optimized design parameters for slotted screen completion and inflow control device (ICD) completion are achieved. These have been compared with the flow models without annulus flow. The following conclusions are drawn.

(1) If extra-pipe packers are not considered, then, for the completion of the slotted sieve tube well, the predicted yield of the variable mass flow model without annulus flow modeling is $9.51 \%$ higher than that of the variable mass flow model with annulus flow modeling. For ICD completion, the predicted yield of the variable mass flow model without annulus flow modeling is $70.98 \%$ higher than that of the variable mass flow calculation model with annulus flow modeling. ICD completion has a higher error than the predictive results of slotted screen completion, with and without considering annulus flow. Both models show that the horizontal pressure profile and flow profile of the borehole wall are more uniform in the wellbore-annulus-reservoir of horizontal wells.

(2) For real well completion, it is observed that several packers outside the ICD completion of the well pipe will only reduce the error in the prediction results between the models with and without annulus flow modeling. The error between the models with and without annulus flow modeling remains significant when packers outside the pipe are considered. The exact error is related to the number and positions of packers outside the pipe, which can be studied further based on the model with annulus flow modeling.

(3) Considering the influence of annulus flow and establishing a model for the corresponding horizontal section with annulus flow modeling are necessary regardless of the slotted screen completion or ICD completion of the well as long as the annulus flow is present in the horizontal section. The flow model 
with annulus flow modeling is the basis for accurately predicting horizontal well production and optimizing the design parameters of slotted screen completion and ICD completion.

(4) The predicted flow profiles of the established models for slotted screen completion and ICD completion are all consistent with those obtained using the $\mathrm{CMG}$ simulator.

\section{ACKNOWLEDGMENT}

Thanks for Luo Wei, the corresponding author for the article. The authors would like to acknowledge the National Natural Science Fund Project (62173049) for key project and the open fund project "Study on transient flow mechanism of fluid accumulation in shale gas wells" of the Sinopec Key Laboratory of Shale Oil/Gas Exploration and Production Technology..

\section{REFERENCES}

Alvarez, A. C., Samad, S. A., Jackson, A. M., Bachar, S., \& Mayer, C. 2014. Wastage Profile Study in Giant Offshore Oilfield, a Well Integrity approach to Optimize ICD Well Completion Design and Improve Corrosion Management for MRC wells, paper SPE171801 presented at the Abu Dhabi International Petroleum Exhibition and Conference, 10-13 November, Abu Dhabi, UAE.

Bol, L., Mccarty, A., Pritchett, J., Sripornprasert, Y., \& Sowmyanarayanan, N. M. 2016. ICD Design Optimisation with Single-Well Dynamic 3D Modelling and Real-Time Operation Support, paper SPE18848 presented at the International Petroleum Technology Conference, 14-16 November, Bangkok, Thailand.

Droppert, V., Hatscher, S., Djayapertapa, L., \& Byrne, M. 2020. Improved Scale Squeeze Placement in Horizontal Wells With Pressure Variations Along the Well Using Non-Newtonian Fluids With Inflow Control Devices, paper SPE200675 presented at the SPE International Oilfield Scale Conference and Exhibition, 24 June, originally scheduled to be held in Aberdeen, Scotland, UK. Due to COVID-19 the physical event was changed to a virtual event.

D Li, Alobedli, A., Selvam, B., Azoug, Y., Obeta, C., \& Nguyen, M., et al. 2017. A New ICD/ICV Well Completion Design Optimizer and Well Management Logic for Full Field Reservoir Simulation with Multiple ICD/ICV wells, paper SPE188642 presented at the Abu Dhabi International Petroleum Exhibition \& Conference, 13-16 November, Abu Dhabi, UAE.

Eltazy, E., Khafiz, M., David, D., \& Peter, G. 2019. Autonomous flow control device modelling and completion optimization, Journal of Petroleum Science \& Engineering, 177, 995-1009, https://doi.org/10.1016/j.petrol.2018.07.042.

Gurses, S. F., Hashemi, M. A., Akhtar, M. N., \& Bellah, S. 2013. ICD Completions` Optimization for an Offshore Abu Dhabi Well Using Dynamic Modeling, paper SPE165962 presented at the SPE Reservoir Characterisation and Simulation Conference and Exhibition, 16-18 September, Abu Dhabi, UAE.

Goh, G., Tan, T., \& Zhang, L. M. 2016. A Unique ICD's Advance Completions Design Solution with Single Well Dynamic Modeling, paper SPE180672 presented at the LADC/SPE Asia Pacific Drilling Technology Conference, 22-24 August, Singapore.

Javid, K., Mustafa, H., Chitre, S., Anurag, A. K., \& Saeed, Y. 2018. Comprehensive ICD/ICV Completion Design Workflow Practiced in Green Oilfield Offshore, paper SPE192645 presented at the Abu Dhabi International Petroleum Exhibition \& Conference, 12-15 November, Abu Dhabi, UAE. 
Liu Xiangping, Guo Chengzhu, Jiang Zhixiang, et al. 1999. The model coupling fluid flow in the reservoir with flow in the horizontal wellbore, ACTA PETROLEI SINICA, 20(03), 82-86. http://www.syxb-cps.com.cn/EN/Y1999/V20/I3/82.

Lorenz, M. D., Ratterman, E. E., \& Augustine, J. R. 2006. Uniform Inflow Completion System Extends Economic Field Life: A Field Case Study and Technology Overview, paper SPE101895 presented at the 2006 SPE Annual Technical Conference and Exhibition, 24-27 September, San Antonio, Texas.

LUO Wei, LIN Yongmao, LI Haitao, JIANG Zujun, WU Qiang, TAO Zhengwu. 2017. ICD completion optimization design of horizontal wells in heterogeneous bottom-water reservoirs, Acta Petrolei Sinica, 38(10):1200-1209.

Luo, W., Li, H. T., Wang, Y. Q., \& Wang, J. C. 2015a. A new semi-analytical model for predicting the performance of horizontal wells completed by inflow control devices in bottom-water reservoirs, Journal of Natural Gas Science \& Engineering, 27, 1328-1339.

Luo, W., Li, H., Wang, Y., Wang, J., \& Yang, M. 2015b. Optimization of the number of openhole packers in horizontal wells completed by inflow control devices for different types of reservoirs, Journal of Engineering Research, 3(1), 30-41.

Maalouf, C. B., Zidan, M., Uijttenhout, M., Hernandez, E. J., Al-Jaberi, S., \& Saeed, Y., et al. 2017. Responsive Design of Inflow Control Devices Completions for Horizontal Wells, paper SPE188794 presented at the Abu Dhabi International Petroleum Exhibition \& Conference, 13-16 November, Abu Dhabi, UAE.

Wanlu Zhang. 2013. The application of ICD in oil rim for improving the production performance of horizontal wells. (dissertation Doctoral, Northeast Petroleum University).

Wei Luo, Ruiquan Liao, Xiuwu Wang, Ming Yang, Weilin Qi, Zilong Liu. 2018. Novel Coupled Model for Productivity Prediction in Horizontal Wells in Consideration of True Well Trajectory, Journal of Engineering Research, 6(4), 1-21.

Shahkarami, A., Friedrichs, M., Iyer, N., Izadi, G., \& Murrell, G. 2020. Utilizing Bayesian Optimization and Machine Learning to Find the Best Inflow Control Design for Horizontal Wells, paper SPE30716 presented at the Offshore Technology Conference, 4 May, originally scheduled to be held in Houston, TX, USA. Due to COVID-19 the physical event was not held. The official proceedings were published online.

Youming Xiong, \& Yingde Pan. 1997. Study on productivity prediction of the horizontal wells with the open hole series of completion method, Journal of Southwest Petroleum University (NATURAL SCIENCE EDITION), 19 (2), 42-46. 